\title{
Selection of the Best Swimming Athletes using MCDM-AHP and VIKOR Methods
}

\author{
Akmaludin $^{1) *}$, Sidik ${ }^{2)}$, Nandang Iriadi $^{\text {3) }}$, Adhi Dharma Surianto ${ }^{4)}$, Andi Arfian ${ }^{5)}$ \\ 1,2,5) Universitas Nusa Mandiri, Jakarta, Indonesia \\ ${ }^{3,4)}$ Universitas Bina Sarana Informatika, Jakarta, Indonesia \\ 1) akmaludin.akm@nusamandiri.ac.id, ${ }^{2)}$ sidik.sdk@nusamandiri.ac.id, ${ }^{3)}$ nandang.ndn@bsi.ac.id \\ ${ }^{4)}$ adhi.ais @ bsi.ac.id, ${ }^{5}$ andi.afn@ nusamandiri.ac.id
}

Submitted : May 22, 2021 | Accepted : June 22, 2021 | Published : Oct 8, 2021

\begin{abstract}
The process of selecting the best swimming athletes is carried out in several test stages. The first is the ability in the four basic swimming styles often contested in international competitions. The second test is the basic physical abilities possessed by a number of swimming athletes. The tests related to the swimming style consist of breaststroke swimming, butterfly swimming, backstroke swimming and crawl stroke swimming, while the plyometrics test consists of banded knee jump, squat jump, jump to the side, and dept jump; due to a large number of selections, a test is required for every athlete. The purpose of this selection is to find the best swimming athletes who will be competed in the international swimming class event. The nine athletes of the Millenium aquatic swimming club that were selected previously are the forerunners of the selected swimming athletes and will be evaluated on a representative basis, which is the best among the nine athletes. The method used in the evaluation and selection process uses two continuous methods, namely the AHP and VIKOR methods. From the results selection assessment, it was found that the best three of the nine nominations selected, the first position selected was AT2 with an index 0.00 , the second position was AT8 with an index 0.25, and the third position was AT7 with an index 0.61. Thus it can be concluded that the AHP and VIKOR methods can be used as decision support to determine optimally in the optimal selection process for swimming athletes.
\end{abstract}

Keywords: Athlete, AHP, Plyometrics, Swimming style, VIKOR.

\section{INTRODUCTION}

Every swimming athlete must often do plyometrics test exercises, and plyometrics is a form of high-intensity training that aims to increase strength and speed towards building power in swimming athletes (Pendidikan \& Dan, 2016). Plyometrics can be done by anyone and can build strength in the leg muscles. Techniques that can be done are the bended knee jump, squat jump, side jump, and dept jump (Shava et al., 2017). This is done to create power, especially in breaststroke swimming. Another important aspect is the starting technique, in which the coaches do not forget how to treat a good start so as to give strong resistance to starting competitions in swimming. The starting technique will build a strong power in the start box. There are several ways to start, namely racing start, swim start, grab start, and tract start (Rasyid et al., 2017). In swimming exercises, you will get used to starting with the help of leg muscles and arm muscles explosively, where the two-leg muscles and arm muscles that are combined will give an explosion against repulsion at start, thus the speed will increase and have a high effect on speed in swimming.

For prepare for the competition in the international event arena, swimming athletes are strived to diligently do exercises on muscle strength both for the leg muscles and hand muscle strength; this is the reason for achieving victory in every competition for swimming athletes, so it is necessary to do serious training to get the expected victory for representatives especially for athletes in the millennium aquatic swimming club. Muscles, indeed legs are very important to be learned by swimming athletes so this plyometrics exercise has a very strong influence on all swimming styles that are used (Annisa, 2020). there is. So that the purpose of this paper is to carry out a selection process for the nine swimming athletes at the Millennial Aquatic Swimming Club, through the application of leg muscle strength tests with the application of the four swimming styles that are contested (Priana, 2019). The measuring instruments used include microtois, stopwatches, and writing instruments. The distance traveled which is the test material is for a distance of 50 meters for the four swimming styles. The results are recorded for data analysis using the Analyze Hierarchical Process (AHP) method associated with the VIKOR method (Wibawa et al., 2019), (Dincer \& Hacioglu, 2013). These two methods are groups of Multi-Criteria Decision Making (MCDM) and have the same role in both methods, namely for the selection process and

*name of corresponding author 
evaluation of all processes and activities that indicate ranking (Thipparat \& Thaseepetch, 2013), thus both AHP and VIKOR methods can collaborate into a single method that can deal with problems related to the selection process for swimming athletes (Yang et al., 2017)for all swimming styles that are often competed in national and international high-level competitions, especially regarding existing swimming style variants.

\section{LITERATURE REVIEW}

\section{Multi-criteria Decision Making-Analytic Hierarchical Process (MCDM-AHP)}

Analytic Hierarchical Process (AHP) is a method used to solve problems that are qualitative and quantitative and can even handle problems that are a combination of the two (Brugha, 2004). AHP that will be used is AHP which is Multi-Criteria (Saaty, 2008), which means that the problem uses many criteria. This is what makes it difficult to determine the priority of many of these criteria (Thipparat \& Thaseepetch, 2013). Therefore, all complicated problems must be simplified by using the hierarchy model (Brugha, 2004), because, with this hierarchy, it will be easier and simpler to determine the weight of each of a number of alternatives based on a number of criteria used as a barometer of measurement (Velasquez \& Hester, 2013) (Ishizaka \& Labib, 2011). Each hierarchy will provide a value called an eigenvector, of course, the eigenvector, which is applied using the Multi-Criteria Decision Making (MCDM) method is of course to get the optimal eigenvector (Alonso \& Lamata, 2006), (Dincer \& Hacioglu, 2013). The optimal eigenvector is the provision of a value for the eigenvector that does not have a difference to the last eigenvector with the previous eigenvector value that has gone through the iteration stage in multiplying pairwise matrices in each hierarchy level. Multiplication of matrices can be done by squaring pairwise matrices (1) with the same matrices, and the results will be stored in certain matrices, then the resulting material must be squared, and the results will be saved in certain matrices. The two certain matrices will be processed by determining normalization to get the eigenvector value. If there is a difference between the two, then multiplication must be done again from the second particular matrices and so on until you find the optimal eigenvector value. To get the optimal eigenvector value, of course, you will go through the iteration stage in multiplying pairwise matrices. Several formulations that can be used with the MCDM-AHP method are determining pairwise matrices, which are arranged based on the hierarchical model created (Ghaleb et al., 2020). The pairwise matrices that are set must follow the rules of Thomas L. Saaty with an order that is adjusted to the value of the Random Index (RI). Note that the RI table that is applied in table-1 has been determined internationally, the amount of which is adjusted to each order of the matrices. Previously there are several important things to determine the consistency of the final result whether a temporary decision is acceptable or not, namely by looking for the Consistent Index (CI) in (2) combined with the Random Index value to obtain the Consistency Ratio (CR) applied to (3) (The et al., 1936). The results obtained through the calculation of mathematical algebram matrices can be tested using the expert choice application .

$$
\begin{gathered}
M_{(r, s)}=\left[\begin{array}{ccccc}
x_{(1,1)} & x_{(1,2)} & x_{(1,3)} & \ldots & x_{(1, s)} \\
x_{(2,1)} & x_{(2,2)} & x_{(2,3)} & \ldots & x_{(2, s)} \\
x_{(3.1)} & x_{(3,2)} & x_{(2,4)} & \ldots & x_{(3, s)} \\
\vdots & \vdots & \vdots & & \ddots \\
x_{(r, 1)} & x_{(r, 2)} & x_{(r, 3)} & \ldots & x_{(r, s)}
\end{array}\right] \\
C I=\frac{(\lambda \max -\mathrm{n})}{(n-1)} \\
C R=\frac{C I}{C R}
\end{gathered}
$$

Table 1

Random Index

\begin{tabular}{ccccccccccc}
\hline Ordo & 1 & 2 & 3 & 4 & 5 & 6 & 7 & 8 & 9 & 10 \\
RI & 0.00 & 0.00 & 0.58 & 0.90 & 1.12 & 1.24 & 1.32 & 1.41 & 1.45 & 1.48 \\
\hline
\end{tabular}

*name of corresponding author 


\section{VIKOR}

VIKOR is a method that can be used for ranking selection using the index system (Umar \& Samir, 2019), where the highest rank is determined by the smallest index magnitude or zero value. The VIKOR method applies the concept of elimination which is very different from the others, and the VIKOR method emphasizes the indexed system. Where is the indexed system, which is ascending index, by determining the amount of determination of the index at the accumulation stage (Mardani et al., 2016), (Ramezaniyan et al., 2012). In the process, the VIKOR method has fairly simple stages, but only at the Si and Ri acquisition stages, where these dimensions will be used after the normalization stage has been carried out on the dataset. The obstacle that often occurs is understanding in determining the criteria on the dataset because each criterion in the dataset has two basic understandings where many researchers assume that all data are the same, even though they are not. There is a criterion that has an inverse meaning that the smallest is the best. This can happen in terms of time. As is the case in this study, to calculate the fastest athlete in the calculation of time, of course, the athlete who has the smallest time value that describes the fastest athlete in the swimming race, so this will be a determination that the smallest value seen on the stopwatch is the best. In general, the greatest value is the best value. So that the normalization that is carried out is of course also different from the others. Agree that there are two assessment assumptions, namely 1) the largest value is the best and pay attention 4) which explains that the largest value is the best, and 2) the smallest value is the best value and pay attention (5) which explains that the smallest value is the best value. This study will apply both understandings. These two things must distinguish in the normalization process of each row of data, this is so that they have the same meaning that is parallel. If you use the amount of comparison for each criterion, determine it first by multiplying it according to the importance value of each criterion by the dimension $\mathrm{v}$ listed in (6). In the process of determining the maximum value dimensioned by $\mathrm{Si}$, pay attention (7) and the maximum magnitude of each row of normalized data Ri from each row in determining it (Sasanka \& Ravindra, 2015), pay attention (8).

$$
\begin{aligned}
& H_{(i, j)}=\frac{\left(A_{(i, j)}-A^{\prime}{ }_{j}\right)}{\left(A^{*} j^{-A^{\prime}}{ }_{j}\right)} \\
& L_{(i, j)}=\frac{\left(A_{(i, j)}-A^{*} j\right)}{\left(A^{\prime}{ }_{j}-A^{*}\right)} \\
& v=R_{i} * W \\
& S_{i}=\sum_{j=1}^{n} W_{j} R_{(i, j)} \\
& R_{i}=\operatorname{Max}_{j}\left[W_{j} \times R_{(i, j)}\right] \\
& Q_{i}=\left[\frac{S_{i}-S^{\prime}}{S^{*}-S^{\prime}}\right] \times V+\left[\frac{R_{i}-R^{\prime}}{R^{*}-R^{\prime}}\right] \mathrm{x}(1-\mathrm{v})
\end{aligned}
$$

For every dataset that has been determined $\mathrm{Si}$ amount and $\mathrm{Ri}$ amount, of course, it will be easy to determine the smallest value of each amount and the largest value of each amount of line. it is also easy to determine the smallest value of the maximum every line and also the largest value of the maximum of each line. that can last determine index value amount on the overall data with the value of $\mathrm{v}$ can be determined based on certain provisions or use the same comparison of fifty percent of each amount. So that index Vikor will be easily according to the formula listed in (9).

\section{METHOD}

In the VIKOR method, it can be described in a simple way to be able to understand and understand the processes, there are several stages that are explained step by step, and this can be said to be an algorithm for using the VIKOR method (Haji et al., 2019). These stages involve using the VIKOR method in detail and in detail through the stages listed in fig.1. Step by step is explained in stages and what is unique in the VIKOR algorithm is the separation process between understanding the largest value is the best, and the smallest value is the best; this is done so that the unification process must be normalized first so that the calculation process can be done with one angle. View the same or in line. Thus the normalization process can be carried out easily to produce a good integration into normalization. Thus the normalization table will be formed into a complete unit and ready to be processed in the calculation of the VIKOR method until the final determination of the ranking process, in

*name of corresponding author 
determining the weight with normalization data, calculating the value of $\mathrm{Ri}$, calculating the value of $\mathrm{Si}$ to determining the amount of the value of Qi.

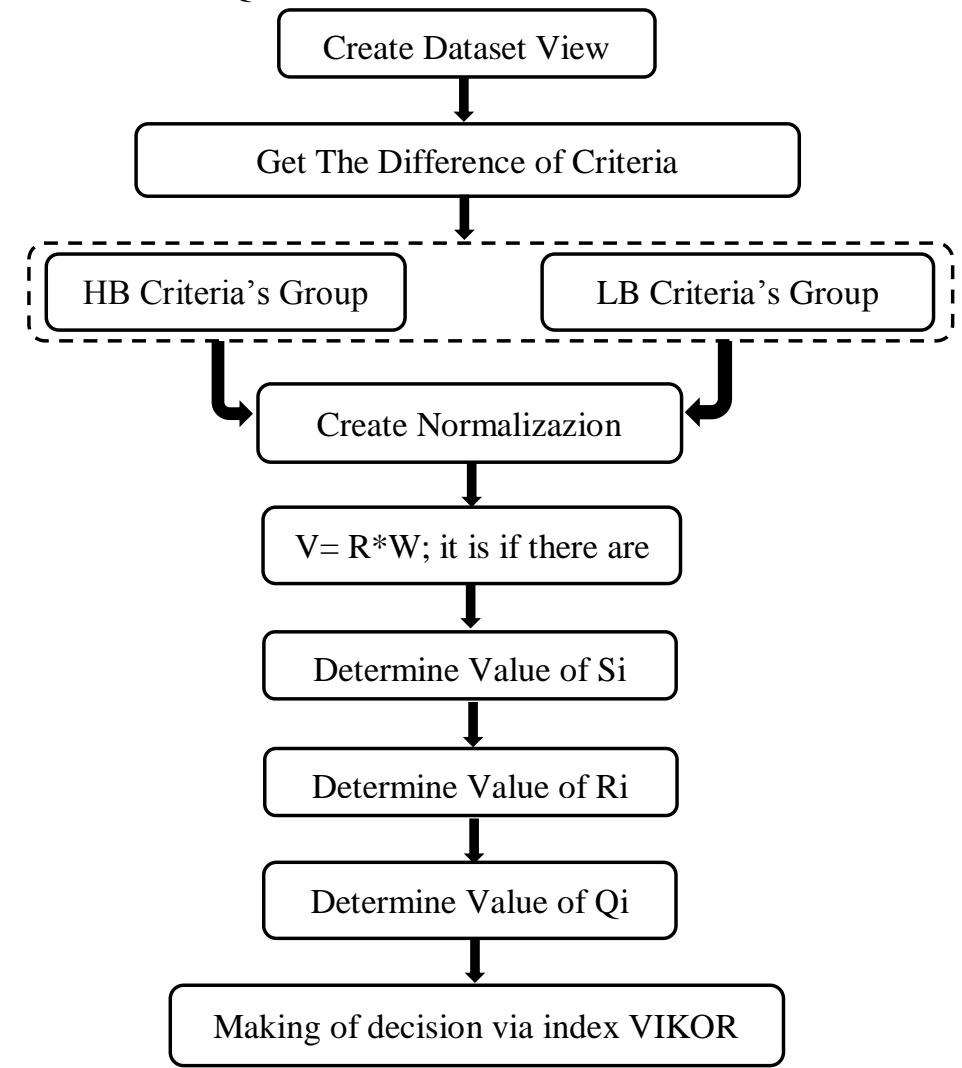

Fig. 1. VIKOR Algorithm.

\section{RESULT}

Departing from the establishment of a dataset view which is a snippet of swimming athletes at the Millennial Aquatic Swimming Club who developed techniques in four swimming styles that are based on the development of leg muscles and hand muscles, into a unique study in increasing the explosion that provides a strong thrust in each. Swimming style. Of the nine athletes who were candidates for swimming style athletes with measurements using tools such as microtoise, stopwatch, and writing instruments to record the results for each swimming stroke with a special distance of 50 meters. The measurement taken is plyometrics, which is a form of high-intensity training that aims to increase strength and speed towards power building for each swimming athlete. Testing is done by taking four swimming styles, namely freestyle, breaststroke, backstroke and butterfly stroke, plus four plyometrics techniques, namely banded knee jump, squat jump, jump to the side, and dept jump. This will be applied with a combination method between AHP and VIKOR, of course, with the conditions listed in table-2, while the results obtained are described in a dataset view, pay attention table-3. Several things need to be considered in Fig. 2 with an explanation of the criteria for the following criteria:

Table 2

Rool of criteria

\begin{tabular}{clc}
\hline Acronim & Criteria & Category \\
\hline GB & Crawl stroke (CS) & LB \\
GD & Breast stroke (BS) & LB \\
GK & Butterfly strok (BT) & LB \\
GP & Back crawl (BC) & LB \\
BJ & Banded Knee Jump (BJ) & HB \\
SJ & Squat Jump (SJ) & HB \\
JS & Jump to Side (JS) HB \\
DJ & Dept Jump (DJ) & HB \\
\hline
\end{tabular}

*name of corresponding author 
While the dataset view generated from nine athletes provides a detailed description of the results of the acquisition of microtois and stopwatch with the results shown in (table-3) but (table 4) as a form of normalization of the dataset view. To determine the importance value of the four swimming styles and leg muscle strength with plyometrics, it is assisted by determining each of its important values with the help of the Analytic Hierarchy Process (AHP) method. In this case, it is divided into two parts, namely, to determine the importance value of the four swimming styles and the importance value for testing with plyometrics. This is done to determine the importance value of each criterion. Note (table-5) which is a pairwise matrix of four swimming styles processed using algebra matrices mathematically, the calculation results occur in five iteration stages to get the optimal eigenvector value, as for the final results obtained for the value $\lambda$ max, optimal eigenvector, consistency index, and the consistency ratio can be seen in (table-5) and included with the eigenvector value calculation using the expert choice application in (figure-2), whereas to determine the importance value related to the plyometrics results with the four criteria used can be seen in (Table-6) with a total of five iterations to get the optimal eigenvector value using algebra matrices mathematically and included with the eigenvector value calculation using the expert choice application in (figure-3).

Table 3

Dataset View

\begin{tabular}{ccccccccc}
\hline $\begin{array}{c}\text { Criteria } \\
\text { (Alt) }\end{array}$ & $\begin{array}{c}\text { CS } \\
(\mathrm{LB})\end{array}$ & $\begin{array}{c}\text { BS } \\
(\mathrm{LB})\end{array}$ & $\begin{array}{c}\text { BT } \\
(\mathrm{LB})\end{array}$ & $\begin{array}{c}\text { BC } \\
(\mathrm{LB})\end{array}$ & $\begin{array}{c}\text { BJ } \\
(\mathrm{HB})\end{array}$ & $\begin{array}{c}\text { SJ } \\
(\mathrm{HB})\end{array}$ & $\begin{array}{c}\text { JS } \\
(\mathrm{HB})\end{array}$ & $\begin{array}{c}\text { DJ } \\
(\mathrm{HB})\end{array}$ \\
\hline AT1 & 80.96 & 72.66 & 78.52 & 79.77 & 35 & 22 & 43 & 30 \\
AT2 & 97.92 & 80.88 & 84.57 & 73.54 & 27 & 24 & 35 & 34 \\
AT3 & 73.76 & 77.16 & 82.83 & 75.15 & 32 & 31 & 42 & 31 \\
AT4 & 68.32 & 76.32 & 83.50 & 82.78 & 25 & 26 & 29 & 27 \\
AT5 & 81.28 & 75.90 & 73.54 & 75.78 & 37 & 32 & 36 & 26 \\
AT6 & 89.68 & 61.32 & 88.71 & 66.75 & 33 & 28 & 32 & 32 \\
AT7 & 82.08 & 69.12 & 89.89 & 60.66 & 28 & 33 & 35 & 28 \\
AT8 & 88.40 & 69.36 & 77.46 & 73.75 & 31 & 25 & 28 & 30 \\
AT9 & 82.80 & 61.92 & 73.54 & 75.01 & 32 & 30 & 34 & 32 \\
\hline
\end{tabular}

Table 4

Normalization

\begin{tabular}{ccccccccc}
$\begin{array}{cccccc}\text { Type } \\
\text { Criteria }\end{array}$ & $\begin{array}{c}\text { GB } \\
\text { (LB) }\end{array}$ & $\begin{array}{c}\text { GD } \\
\text { (LB) }\end{array}$ & $\begin{array}{c}\text { GK } \\
(\text { LB })\end{array}$ & $\begin{array}{c}\text { GP } \\
(\mathrm{LB})\end{array}$ & $\begin{array}{c}\text { SU } \\
(\mathrm{HB})\end{array}$ & $\begin{array}{c}\text { PU } \\
(\mathrm{HB})\end{array}$ & $\begin{array}{c}\text { SJ } \\
(\mathrm{HB})\end{array}$ & $\begin{array}{c}\text { PU } \\
(\mathrm{HB})\end{array}$ \\
\hline (Alt) & 0.42 & 0.29 & 0.17 & 0.11 & 0.38 & 0.28 & 0.20 & 0.13 \\
\hline AT1 & 0.57 & 0.42 & 0.30 & 0.86 & 0.83 & 0.00 & 1.00 & 0.50 \\
AT2 & 0.00 & 0.00 & 0.67 & 0.58 & 0.17 & 0.18 & 0.47 & 1.00 \\
AT3 & 0.82 & 0.19 & 0.57 & 0.66 & 0.58 & 0.82 & 0.93 & 0.63 \\
AT4 & 1.00 & 0.23 & 0.61 & 1.00 & 0.00 & 0.36 & 0.07 & 0.13 \\
AT5 & 0.56 & 0.25 & 0.00 & 0.68 & 1.00 & 0.91 & 0.53 & 0.00 \\
AT6 & 0.28 & 1.00 & 0.93 & 0.28 & 0.67 & 0.55 & 0.27 & 0.75 \\
AT7 & 0.54 & 0.60 & 1.00 & 0.00 & 0.25 & 1.00 & 0.47 & 0.25 \\
AT8 & 0.32 & 0.59 & 0.24 & 0.59 & 0.50 & 0.27 & 0.00 & 0.50 \\
AT9 & 0.51 & 0.97 & 0.00 & 0.65 & 0.58 & 0.73 & 0.40 & 0.75 \\
\hline
\end{tabular}

Table 5

Eigenvector swimming style using algebra matrices

\begin{tabular}{lccccc}
\hline Swimming Style & BS & BT & BC & CS & Eigenvector \\
\hline Breast Stroke (BS) & 1.000 & 1.632 & 2.760 & 3.000 & 0.424 \\
Butterfly Stroke (BT) & 0.613 & 1.000 & 1.823 & 2.852 & 0.294 \\
Back Crawl (BC) & 0.362 & 0.549 & 1.000 & 1.802 & 0.170 \\
Crawl Stroke (CS) & 0.333 & 0.351 & 0.555 & 1.000 & 0.112 \\
\hline \multicolumn{1}{c}{$\lambda$ max $=$} & 4.030 & $\mathrm{CI}=$ & 0.010 & $\mathrm{CR}=$ & 0.011
\end{tabular}

*name of corresponding author 


\section{Breast Stroke \\ Butterfly Stroke \\ BackCraul \\ Croil Stroke \\ Inconsistency $=0.01$ \\ with 0 missing judgments.}

Fig. 2. Eigenvector swimming style using expert choice application

Table 6

Eigenvector plyometrices using algebra matrices

\begin{tabular}{lcrccc}
\hline \multicolumn{1}{c}{ Plyometrics } & BJ & SJ & JS & DJ & Eigenvector \\
\hline Banded Knee Jump (BJ) & 1.000 & 1.636 & 1.895 & 2.437 & 0.384 \\
Squat Jump (SJ) & 0.611 & 1.000 & 1.745 & 2.039 & 0.282 \\
Jump to Side (JS) & 0.528 & 0.573 & 1.000 & 1.798 & 0.199 \\
Dept Jump (DJ) & 0.410 & 0.490 & 0.556 & 1.000 & 0.134 \\
\hline \multicolumn{1}{c}{$\lambda \max =$} & 4.035 & $\mathrm{CI}=$ & 0.012 & $\mathrm{CR}=$ & 0.013 \\
\hline
\end{tabular}

Privities with respect to: Gaek Pyometrics painise

Banded Knee Jump
Squat Jump
Jump to Side
Dept Jump
Inconsistency $=0.01$
with 0 missing judgments.

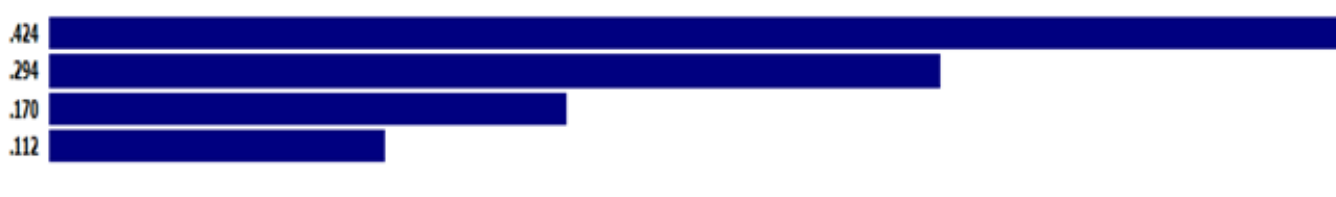

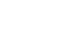

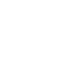


Table-7

Multiply Normalizazion by eigenvector

\begin{tabular}{|c|c|c|c|c|c|c|c|c|}
\hline $\begin{array}{c}\text { Type } \\
\text { Criteria }\end{array}$ & $\begin{array}{c}\text { GB } \\
\text { (LB) }\end{array}$ & $\begin{array}{l}\text { GD } \\
\text { (LB) }\end{array}$ & $\begin{array}{c}\text { GK } \\
\text { (LB) }\end{array}$ & $\begin{array}{c}\text { GP } \\
\text { (LB) }\end{array}$ & $\begin{array}{c}\mathrm{SU} \\
(\mathrm{HB})\end{array}$ & $\begin{array}{c}\mathrm{PU} \\
(\mathrm{HB})\end{array}$ & $\begin{array}{c}\text { SJ } \\
(\mathrm{HB})\end{array}$ & $\begin{array}{c}\mathrm{PU} \\
\text { (HB) }\end{array}$ \\
\hline (Alt) & \multicolumn{8}{|c|}{$\mathrm{V}=(\mathrm{Ri} * \mathrm{EV})$} \\
\hline AT1 & 0.24 & 0.12 & 0.05 & 0.10 & 0.32 & 0.00 & 0.20 & 0.07 \\
\hline AT2 & 0.00 & 0.00 & 0.11 & 0.07 & 0.06 & 0.05 & 0.09 & 0.13 \\
\hline AT3 & 0.34 & 0.06 & 0.10 & 0.07 & 0.22 & 0.23 & 0.19 & 0.08 \\
\hline AT4 & 0.42 & 0.07 & 0.10 & 0.11 & 0.00 & 0.10 & 0.01 & 0.02 \\
\hline AT5 & 0.24 & 0.07 & 0.00 & 0.08 & 0.38 & 0.26 & 0.11 & 0.00 \\
\hline AT6 & 0.12 & 0.29 & 0.16 & 0.03 & 0.26 & 0.15 & 0.05 & 0.10 \\
\hline AT7 & 0.22 & 0.18 & 0.17 & 0.00 & 0.10 & 0.28 & 0.09 & 0.03 \\
\hline AT8 & 0.14 & 0.17 & 0.04 & 0.07 & 0.19 & 0.08 & 0.00 & 0.07 \\
\hline AT9 & 0.21 & 0.28 & 0.00 & 0.07 & 0.22 & 0.21 & 0.08 & 0.10 \\
\hline
\end{tabular}

Table 8

Index VIKOR

\begin{tabular}{ccccccccc}
\hline Alt & Si & Ri & $\mathrm{S}^{\prime}$ & $\mathrm{S}^{*}$ & $\mathrm{R}^{\prime}$ & $\mathrm{R}^{*}$ & $\mathrm{Qi}$ & Index \\
\hline AT1 & 1.10 & 0.32 & 0.52 & 1.29 & 0.13 & 0.42 & 0.70 & 4 \\
AT2 & 0.52 & 0.13 & & & & & 0.00 & 1 \\
AT3 & 1.29 & 0.34 & & & & & 0.87 & 9 \\
AT4 & 0.84 & 0.42 & & & & & 0.70 & 7 \\
AT5 & 1.13 & 0.38 & & & & & 0.83 & 8 \\
AT6 & 1.16 & 0.29 & & & & & 0.70 & 5 \\
AT7 & 1.08 & 0.28 & & & & & 0.62 & 3 \\
AT8 & 0.75 & 0.19 & & & & & 0.25 & 2 \\
AT9 & 1.18 & 0.28 & & & & & 0.69 & 6 \\
\hline
\end{tabular}

Tables 8 and 9 illustrate that the dimensions $\mathrm{S}^{\prime}, \mathrm{S}^{*}, \mathrm{R}^{\prime}$, and $\mathrm{R}^{*}$ are only written once, because it means that the dimension $S^{\prime}$ is the lowest value in column $S$ and the dimension $S^{*}$ is the highest value in column $S$. Likewise for the dimension $\mathrm{R}^{\prime}$ as the smallest value in column $\mathrm{R}$, and the dimension $\mathrm{R}^{*}$ as the largest value in column $\mathrm{R}$.

Table 9

Shorting Rank Swimming Athelete

\begin{tabular}{ccccccccc}
\hline Alt & $\mathrm{Si}$ & $\mathrm{Ri}$ & $\mathrm{S}^{\prime}$ & $\mathrm{S}^{*}$ & $\mathrm{R}^{\prime}$ & $\mathrm{R}^{*}$ & $\mathrm{Qi}$ & Rank \\
\hline AT2 & 0.52 & 0.13 & 0.52 & 1.30 & 0.13 & 0.42 & 0.00 & 1 \\
AT8 & 0.75 & 0.19 & & & & & 0.25 & 2 \\
AT7 & 1.08 & 0.28 & & & & & 0.61 & 3 \\
AT1 & 1.10 & 0.32 & & & & & 0.69 & 4 \\
AT6 & 1.16 & 0.29 & & & & & 0.69 & 5 \\
AT9 & 1.18 & 0.29 & & & & & 0.69 & 6 \\
AT4 & 0.84 & 0.42 & & & & & 0.71 & 7 \\
AT5 & 1.14 & 0.38 & & & & & 0.83 & 8 \\
AT3 & 1.30 & 0.35 & & & & & 0.87 & 9 \\
\hline
\end{tabular}

\section{DISCUSSIONS}

Selection using the VIKOR method can be done normally or can be done by using the value of importance to the criteria used, in this research, it was carried out using the help of optimal eigenvalues by using algebra matrices mathematically so that it looks more complex and complicated because That is, if there is indeed an opportunity to re-test without using the value of importance, will it give the same value to the decision results as produced using the eigenvector value that was done. If it does give the same decision, this is a clear form of truth; otherwise, we must pay more attention to the application stated in the VIKOR algorithm steps. While the role of AHP is used

*name of corresponding author 
in two function, the first as a preference in the weighting of each criterion and the second as a multiplier during the normalization weighting process during the process of determining the preference index.

\section{CONCLUSION}

From the problems faced by how to select swimming athletes at the Millennial Aquatic Swimming Club by measuring the application of the four swimming styles to the plyometrics technique so that it can be applied correctly by a swimming athlete in achieving exploration of leg muscle strength and hand muscles. The results obtained from nine swimming athletes using the AHP and VIKOR methods, namely AT2 managed to rank first with the smallest index value, namely 0.00 , while the second position was occupied by AT8 with an index value of 0.25 , while AT7 occupied the third position with an index value of 0.61 . . Thus the collaboration method between the Analytic Hierarchy Process (AHP) and the VIKOR method can provide optimal decisions on the selection and evaluation of nine swimming athletes against the three chosen as winners..

\section{ACKNOWLEDGMENT}

Thank you to my family who wants to support in this research process which is very helpful morally, then to other parties I do not forget to thank Nusa Mandiri University for providing support in the form of motivation to write this article and the publishing party from the editorial staff. Who is willing to accept this article even though it is in such a careful process in selecting the topic until it is published.

\section{REFERENCES}

Alonso, J. A., \& Lamata, M. T. (2006). Consistency in the analytic hierarchy process: a new approach. International Journal of Uncertainty, Fuzziness and Knowledge-Based Systems, 14(4), 445-459. https://doi.org/10.1142/S0218488506004114

Annisa, S. (2020). Kegiatan olahraga aktivitas air. SMAN 3 Medan, 1(1), 1-17.

Brugha, C. M. (2004). Structure of multi-criteria decision-making. Journal of the Operational Research Society, 55(11), 1156-1168. https://doi.org/10.1057/palgrave.jors.2601777

Dincer, H., \& Hacioglu, U. (2013). Performance evaluation with fuzzy VIKOR and AHP method based on customer satisfaction in Turkish banking sector. Kybernetes, 42(7), 1072-1085. https://doi.org/10.1108/K02-2013-0021

Ghaleb, A. M., Kaid, H., Alsamhan, A., Mian, S. H., \& Hidri, L. (2020). Assessment and Comparison of Various MCDM Approaches in the Selection of Manufacturing Process. Advances in Materials Science and Engineering, 2020. https://doi.org/10.1155/2020/4039253

Haji, M., Kamankesh, M. R., Jamshidi, M., Daghineh, M., \& Shaltooki, A. A. (2019). A multi-criteria ranking algorithm based on the VIKOR method for meta-search engines. International Journal on Informatics Visualization, 3(3), 248-254. https://doi.org/10.30630/joiv.3.3.269

Ishizaka, A., \& Labib, A. (2011). Review of the main developments in the analytic hierarchy process. Pre Print Vertion, 38(11), 14336-14345. https://doi.org/10.1016/j.eswa.2011.04.143

Mardani, A., Zavadskas, E. K., Govindan, K., Senin, A. A., \& Jusoh, A. (2016). VIKOR technique: A systematic review of the state of the art literature on methodologies and applications. Sustainability (Switzerland), 8(1), 1-38. https://doi.org/10.3390/su8010037

Pendidikan, F., \& Dan, O. (2016). Pengaruh Latihan Plyometrics Terhadap. 01(01), 6-11.

Priana, A. (2019). Pengaruh Alat Bantu Latihan Pull Buoy Terhadap Prestasi Renang Gaya Dada. Journal of SPORT (Sport, Physical Education, Organization, Recreation, and Training), 3(1), 9-14. https://doi.org/10.37058/sport.v3i1.745

Ramezaniyan, M. R., Kazemi, M., Jafari, H., \& Elahi, S. M. (2012). Application of integrated fuzzy VIKOR \& AHP methodology to contractor ranking. Management Science Letters, 2(5), 1511-1526. https://doi.org/10.5267/j.msl.2012.05.017

Rasyid, H. Al, Setyakarnawijaya, Y., \& Marani, I. N. (2017). Hubungan Kekuatan Otot Tungkai Dan Kekuatan Otot Lengan Dengan Hasil Renang Gaya Bebas 50 Meter Pada Atlet Millennium Aquatic Swimming Club. Jurnal Ilmiah Sport Coaching and Education, 1(1), 71-85. https://doi.org/10.21009/jsce.01106

Saaty, T. L. (2008). Decision making with the analytic hierarchy process. International Journal of Services Sciences, 1(1), 83. https://doi.org/10.1504/IJSSCI.2008.017590

Sasanka, C. T., \& Ravindra, K. (2015). Implementation of VIKOR Method for Selection of Magnesium Alloy to Suit Automotive Applications. International Journal of Advanced Science and Technology, 83, 49-58.

Shava, I., Kusuma, D. W. Y., \& Rustiadi, T. (2017). Latihan Plyometrics dan Panjang Tungkai terhadap Kecepatan Renang Gaya Dada Atlet Renang Sumatera Selatan. Physical Education and Sports, 6(3), 266-271.

*name of corresponding author 
The, F. O. R., Person, L. A. Y., \& Lipovetsky, S. (1936). An Interpretation Of The AHP Eigenvector Solution GfK Custom Research North America 8401 Golden Valley Rd., Minneapolis, MN 55427, USA 2. The AHP solution and its interpretation for the maximum eigenvalue $\lambda$ yields the principal eigenvector $\alpha$ which ser. $2(2), 158-162$.

Thipparat, T., \& Thaseepetch, T. (2013). An integrated VIKOR and fuzzy AHP method for assessing a sustainable research project. World Applied Sciences Journal, 22(12), 1729-1738. https://doi.org/10.5829/idosi.wasj.2013.22.12.2787

Umar, I. K., \& Samir, B. (2019). Cumhuriyet Science Journal CSJ. Cumhuriyet Sci. J., 40(1), $197-203$. https://doi.org/http://dx.doi.org/10.17776/csj.356185

Velasquez, M., \& Hester, P. (2013). An analysis of multi-criteria decision making methods. International Journal of Operations Research, 10(2), 56-66.

Wibawa, A. P., Fauzi, J. A., Isbiyantoro, S., Irsyada, R., Dhaniyar, \& Hernández, L. (2019). VIKOR multi-criteria decision making with AHP reliable weighting for article acceptance recommendation. International Journal of Advances in Intelligent Informatics, 5(2), 160-168. https://doi.org/10.26555/ijain.v5i2.172

Yang, M. H., Su, C. H., \& Wang, W. C. (2017). The use of a DANP with VIKOR approach for establishing the model of e-learning service quality. Eurasia Journal of Mathematics, Science and Technology Education, 13(8), 5927-5937. https://doi.org/10.12973/eurasia.2017.01041a

*name of corresponding author 